\title{
ЗНАЧЕНИЕ ДИНАМИЧЕСКОЙ РЕНТГЕНОЛОГИЧЕСКОЙ ДЕФЕКОГРАФИИ В ДИАГНОСТИКЕ ЗАБОЛЕВАНИЙ ПРЯМОЙ КИШКИ И ТАЗОВОГО ДНА
}

\author{
С. С. Иманова
}

Азербайджанский медицинский университет, г. Баку, Республика Азербайджан

\section{SIGNIFICANCE OF DYNAMICAL ROENTGENOLOGICAL DEFECOGRAPHY IN DIAGNOSIS Of RECTAL AND THE PELVIC FLOOR DISEASES}

\author{
S. S. Imanova
}

Azerbaijan Medical University, Baku, Republic of Azerbaijan

\begin{abstract}
Реферат
У 124 женщин при заболеваниях прямой кишки и патологических состояниях тазового дна в алгоритм предоперационного обследования включена динамическая рентгенологическая дефекография (ДРД), изучены ее диагностические возможности. Результаты ДРД оценивали в сравнении с таковыми других методов исследования (ректо-, ректосигмоскопия, колонофиброскопия, эндоректальное и интравагинальное УЗИ, МРТ малого таза, сфинктерометрия и др.), выбраны соответствующие лечебная (оперативная) тактика, методы и объем вмешательства. У 75 (54,8\%) пациенток выявлено ректоцеле III и II степени, у 17 (13,7\%) - пролапс прямой кишки, у 15 (12,1\%) - ее слизистой оболочки, у 6 (4,8\%) - энтероцеле, у 5 (4,0\%) - внутренняя инвагинация, у 4 (3,2\%) - анисмус (нарушение координации мышц тазового дна при дефекации). Чувствительность ДРД составила $85,7 \%$, специфичность - 91,9\%, точность - 95,3\%.

Ключевые слова: ректоцеле; пролапс слизистой оболочки; выпадение прямой кишки; аноректальной угол; дефекография.

Abstract

Dynamical roentgenological defecography (DRD) and its diagnostic possibilities in algorithm of preoperative examination studying was conducted in124 women, suffering rectal diseases and pathological states of pelvic floor. The DRD results were estimated in comparison with such of other methods of investigation (recto-, rectosygmoscopy, colonofibroscopy, endorectal and intravaginal USG, MRT of small pelvis, sphincterometry, etc.), and a certain treatment (operative) tactics, methods and volume of intervention were choosed. In 75 (54.8\%) patients rectocele of degree III and degree II was revealed, in $17(13.7 \%)$ - rectal prolapse, in $15(12.1 \%)$ - prolapse of rectal mucosa, in $6(4.8 \%)$ - enterocele, in $5(4.0 \%)$ - internal invagination, in $4(3.2 \%)$ - anismus (disorder of coordination of the pelvic floor muscles while defecation). Sensitivity of DRD have constituted $85.7 \%$, specificity $-91.9 \%$, accuracy $-95.3 \%$.

Keywords: rectocele; mucosal prolapse; rectal prolapse; anorectal angle; defecography.
\end{abstract}

Динамическая рентгенологическая дефекография (ДРД) - визуализирующий уточняющий метод диагностики заболеваний и патологических состояний прямой кишки, особенно тазового дна. В специальной литературе используют также термины «әвакуационная проктография» [1], «динамическая проктография» [2], «релаксационная проктография» [3].

Метод предложен и описан в 1952 г. L. Wallden для изучения влияния аномально глубокого прямокишечно-маточного углубления на изменения дефекации [4]. В последующем опубликованы результаты многочисленных исследований, посвященные роли ДРД в диагностике некоторых хирургических заболеваний прямой кишки, в частности, ее опущения [5 - 7].

В конце прошлого века требования по улучшению медицинского обслуживания населению, в том чис- ле больных проктологического профиля, особенно в развитых странах возросли, соответственно, изменены и скорректированы лечебно-диагностические подходы к их лечению. В связи с этим возник интерес к методу ДРД для обеспечения визуализации естественного опорожнения прямой кишки, диагностики нарушений ее моторно-эвакуаторной функции и состояния параректальных анатомических структур, в частности, тазового дна в динамике и в покое [8, 9]. В РФ впервые метод внедрен в клиническую практику в НИЦ колопроктологии в 2002 г. [10], через 9 лет в ЦКГ ГосТаможКомитета Республики Азербайджан, в колопроктологической секции Учебно-хирургической клиники - с мая 2014 г.

Результаты ДРД во время дефекации, при натуживании и в покое дают ценную информации об анатомо-физиологическом состоянии прямой кишки, заднепроходного канала и сфинктерного комплекca, их отношении к смежным органам (влагалище, матка, мочевой пузырь) и анатомическому тазу. При слабости мышцы, поднимающей задний проход (m. levator ani), аноректальный угол смещается вниз во время натуживания [8], в покое лобково-прямокишечная мышца (m. puborectalis) расслабляется, и угол увеличивается. Заднепроходный канал расширяется при расслаблении замыкающего аппарата прямой кишки. При одновременном расслаблении мышц, вследствие повышения внутрибрюшного давления, прямокишечно-заднепроходная часть приобретает воронкообразный вид, возникает физиологический акт дефекации. Состояние прямой кишки и величина аноректального угла, их нарушения зависят от состояния мышц тазового дна. Уменьшение аноректального угла в условиях патофизиологических изменений та- 
зового дна и промежности проявляются различными патологическими и/или парадоксальными реакциями. Функциональные расстройства расслабляющих мышц, связанные с заболеваниями промежностно-тазово-ректального комплекса, а также психоэмоциональными факторами, обусловливают нарушения дефекации, запор органической или функциональной природы. Сам процесс дефекации у таких пациентов начинается, продолжается и завершается (не всегда) чрезмерным натуживанием. Длительное натуживание чревато аноректальной дисфункцией, в последующем - ректоцеле, пролапсом слизистой оболочки и прямой кишки, вследствие чего возникают ишемия тканей, затем изъязвление выпавшей части слизистой оболочки и прямой кишки.

Таким образом, изучение и видео(фото)документирование изменений ДРД позволяют изучить анатомо-функциональное состояние прямой кишки, тазового дна и промежности. ДРД является высокоинформативным методом визуализационной диагностики при заболеваниях этого комплекса.

Целью исследования явилось изучение результатов ДРД у пациенток при органических нарушениях дефекации.

\section{МАТЕРИАЛЫ И МЕТОДЫ ИССЛЕДОВАНИЯ}

В период с 2014 по 2017 г. в колопроктологической клинике лечили 124 пациенток в возрасте от 22 лет до 81 года, в среднем $(38,4 \pm 2,7)$ года, с заболеваниями прямой кишки и тазового дна, в том числе 71 (57,3\%) - репродуктивного и активного трудоспособного возраста. Ректоцеле III степени диагностировано у 69 (55,6\%) пациенток, II степени - у 6 (4,8\%), пролапс прямой кишки - у 17 (13,7\%), ее слизистой оболочки - у 15 (12,1\%). Длительность заболевания от 3 мес до 31 года, в среднем $(8,45 \pm 1,1)$ года.

ДРД внедрена в алгоритм предоперационного обследования пациенток, включена в процесс диагностики у больных, которые жаловались на запор, болезненную, длительную или неполную дефекацию, дефекацию с помощью введенно- го во влагалище указательного пальца, недержание кала и газов, кровотечение во время и после дефекации, слизистые выделения до или после опорожнения, наличие или ощущение наличия инородного тела (объемной массы) в заднепроходном канале или промежности и др.

Статистическая обработка данных проведена с использованием статистического пакета SPSS Inc версия 20.0. Количественные переменные анализировали с помощью критерия $\chi^{2}$ Pearson и теста MannWhitney.

Чувствительность и специфичность метода вычисляли по формулам: чувствительность $=$ a/a+c, специфичность $=\mathrm{d} / \mathrm{b}+\mathrm{d}$,

где:

a - положительный результат;

b - ложноположительный результат;

с - ложноотрицательный результат;

$\mathrm{d}$ - отрицательный результат.

Методика ДРД. За сутки до исследования больным назначали слабительные препараты, утром перед исследованием проводили очистительную клизму. В положении пациентки сидя в прямую кишку с помощью шприца объемом 100 мл вводили 200-250 мл пастообразной бариевой взвеси до появления чувства дефекации. Затем пациентка опорожняла прямую кишку в специально приспособленный унитаз. В покое, во время волевых сокращений и дефекации получали боковые снимки, снимали видеофильм процесса исследования. Для определения величины аноректального угла и степени опущения тазового дна дополнительно во влагалище вводили бариевый гель. При нормальной дефекации аноректальный угол увеличивался, 90 - 100\% контрастного вещества выводилось наружу. Выявляли основные симптомы и физические параметры: возвышение передней и/или задней стенки прямой кишки; соотношение аноректальной области к пубококцигеальной оси в покое, при волевых сокращениях, натуживании и дефекации; величину аноректального угла; лабильность слизистой оболочки и стенки прямой кишки, ее релаксацию и выпадение; продолжительность эвакуации контрастного вещества; его остаточный объем. Продолжительность исследования 15 - 20 мин, доза облучения $4-8,5$ м3в.

По данным ДРД вычисляли такие анатомо-геометрические показатели: аноректальный угол (угол, образующийся между линиями, проходящими по задней стенке прямой кишки и заднепроходного канала). В покое он составил $90-100^{\circ}$. При сокращении сфинктеров и мышц тазового дна угол становится острым $\left(70-90^{\circ}\right)$, во время дефекации - слепым (110-180); степень опущения тазового дна - при натуживании тазовое дно поднимается, после дефекации - опускается. Ее измеряют по соотношению к пуборектальной оси. В норме тазовое дно опускается до 4 см ниже оси; длина (в норме 7-8 см) и ширина (в норме до 2,5 cм) заднепроходного канала - измеряют в момент максимальной эвакуации контрастного вещества.

Во время и после эвакуации обнаруживают такие патологические состояния: анисмус (диссинергия мышц тазового дна). Иногда выявляют ложноотрицательные результаты; ректоцеле - возвышение прямой кишки в сторону влагалища во время эвакуации и при натуживании. В клинической практике имеет значение ректоцеле более 3 см; сигмоидоцеле - опущение сигмовидной ободочной кишки и ее части до прямокишечно-маточного углубления; энтероцеле - опущение петли (петель) тонкой кишки вместе с брюшиной в прямокишечно-маточное углубление (пролапс брюшины); пролапс прямой кишки - полное, частичное или скрытое выпадение прямой кишки; мегаректум - ширина прямой кишки более 9 см. Прямая кишка практически не опорожнена; синдром опущения тазового дна - степень опущения более 4 см; недержание кала - быстрое опорожнение без сопротивления, натуживания, даже в покое.

\section{РЕЗУЛЬТАТЫ И ИХ ОБСУЖДЕНИЕ}

По данным ДРД у 75 (60,5\%) пациенток выявлено ректоцеле III и ІІ степени, у 17 (13,1\%) - пролапс прямой кишки, у 15 (12,1\%) - ее слизистой оболочки, у 6 (4,8\%) - энтероцеле, у 5 (4,0\%) - внутренняя инвагинация 
прямой кишки, у 4 (3,3\%) - анисмус, у 2 (1,6\%) - сигмоидоцеле. Результаты ДРД и других методов исследования (ректо-, ректосигмоидоскопия, колоноскопия, эндоректальное и интравагинальное УЗИ и МРТ органов малого таза, сфинктерометрия и др.) оценивали комплексно, на основании их анализа выбраны соответствующие тактика, метод и объем хирургического вмешательства. Инвагинация прямой кишки, внутренние геморроидальные узлы, частичный и циркулярный пролапс слизистой оболочки у всех больных сопутствовали ректоцеле. Изолированную внутреннюю инвагинацию, выпадение внутренних геморроидальных узлов и слизистой оболочки прямой кишки не наблюдали. Одновременно существование 2 - 3 заболеваний прямой кишки и более обусловлены общей слабостью и релаксацией мышц тазового дна.

Сочетанные заболевания из-за тяжести клинических проявлений (запор, кровотечение, дискомфорт в области промежности и др.) являлись основной причиной обращения за медицинской помощью. Продолжительность эвакуации контрастного вещества и его остаточный объем имеют важное значение при выборе хирургической тактики.

Большой объем остаточного контрастого вещества является основным информативным диагностическим критерием истощения функциональных резервов тазового дна и опорожняющего мышечного комплекса (аппарата) прямой кишки. Длительность имитационной дефекации от нескольких минут до 1 2 ч (в норме 6 - 30 с), объем остаточного контрастого вещества 30
- 70\% введенного объема (в норме 10 - 20\%). При ректоцеле II степени эти показатели составляли соответственно 3 - 7 мин и $30-39 \%$, III степени - 8 - 15 мин и $40-70 \%$, различия статистически достоверны (р $<0,001)$ по сравнению с дефекографическими геометрическими параметрами (величина аноректального угла, длина и ширина заднепроходного канала, степень опущения тазового дна).

Мы, как и многие авторы, переднее или заднее возвышение стенки прямой кишки до 2 см, инвагинацию до 1 см считаем нормой только в ситуациях, когда полное или близкое к полному опорожнение возникает в короткие сроки (максимум, 1 2 мин). Тем не менее, таким пациентам рекомендуем физиотерапевтические процедуры и продолжительные лечебно-тренировочные курсы для укрепления тазового дна.

Переднее ректоцеле III степени (возвышение стенки прямой кишки более 4 см) выявлено у 58 (46,8\%) пациенток, II степени (2 - 4 см) - у 4 (3,3\%). Основание возвышения располагалось на линии, проходящей вдоль расслабленной стенки. Расстояние от верхушки до этой линии определяет степень ректоцеле.

Выпадение слизистой оболочки и прямой кишки отмечено соответственно у 15 (12,1\%) и 17 (13,7\%) больных. В зарубежных научных изданиях в последнее время уделяют внимание трудностям определения степени выпадения прямой кишки и ее слизистой оболочки вследствие быстрых изменений рентгенологических изображений, большой разницы плотности тканей тазового дна и воздуха вокруг выпавшей пря- мой кишки. Для устранения этого затруднения мы наносим вокруг заднепроходного отверстия бариевую пасту, на дефекограммах она имеет вид поперечной плоскости, соответствущей границам этих структур, при этом выпавшая часть прямой кишки или ее слизистой оболочки располагается ниже (кнаружи) от этой плоскости. Длина этой части соответствует степени выпадения органа (его слизистой оболочки). В целях определения границы можно использовать металлический листок (проволоку).

Введение во влагалище пропитанного бариевой пастой тампона перед исследованием может спровоцировать изображение из-за давления на ослабленную стенку прямой кишки. Этот недостаток устранен путем введения во влагалище бариевого геля из расчета 100 - 150 мл, при этом давление на переднюю стенку прямой кишки тампоном исключается.

\section{выводы}

1. Информативность ДРД в диагностике хирургических заболеваний и патологических состояний прямой кишки и тазового дна высокая: чувствительность - 85,7\%, специфичность - 91,9\%, точность $95,3 \%$.

2. После устранения недостатков ДРД частота искаженных и ошибочных результатов снизилась до минимума.

3. Интерпретация и комплексная оценка результатов ДРД и данных других визуализационных методов исследования имеет важное клиническое значение при выборе лечебной (хирургической) тактики, спо-

\section{REFERENCES}

1. Najjia NM, Joshua ISB, Cary BA, Carter EP, Skandan Sh, Robert D. Colon and Rectum. In: Sabiston Textbook of Surgery, 2017. Ch 51:1312-93.

2. Gazzani SE, Marcantoni EA, Capretti G, Trunfio V, Bacchini E, Artioli $G$, et al. Defecography: a still needful exam for evaluation of pelvic floor diseases. Acta Biomed. 2016 January 1; 87 suppl 3:34-9. PMID: 27467865

3. van Diepen DA, Huisman TW, Langkemper R, Boutkan H. Barium impaction after defecography: an unusual case with a patient' request to bowel resection. Int J Colorect Dis. 2016 Aug;31(8):1521-2. doi: 10.1007/s00384-016-2541-6. Epub 2016 Mar 7.

4. Wallden L. Defecation block in cases of deep rectogenital pouch. Acta Chir Scand. 1952 Oct;48(40): 1397.

5. Flusberg MV, Sahni SM, Erturk K, Mortele J. Dynamic MR defecography: Assessment of the usefulness of the defecation phase. Am J Roentgenol. 2011 Apr;196(4):W394-9. doi: 10.2214/AJR.10.4445.
6. Olson C. Diagnostic testing for fecal incontinence. Clin Colon Rectal Surg. 2014 Sep;27(3):85-90. doi: 10.1055/s-0034-1383901

7. Nikjooy A. MR defecography, a diagnostic test to evaluate the pelvic floor motion in patients with dyssynergic defecation after biofeedback therapy. J Pain Relief. 2016;5:236. doi:10.4172/21670846.1000236.

8. Zhang SC, Wang WL, Liu X. Defecography used as a screening entry for identifying evacuatory pelvic floor disorders in childhood constipation. Clin Imaging. 2014 Mar-Apr;38(2):115-21. doi: 10.1016/j. clinimag.2013.11.010.

9. Beer-Gabel M, Carter D. Comparison of dynamic transperineal ultrasound and defecography for the evaluation of pelvic floor disorders. Int J Colorect Dis. 2015 Jun;30(6):835-41. doi: 10.1007/s00384015-2195-9.

10. Zarodnyuk IV. Rentgenologicheskaya defekografiya v obsledovanii koloproktologicheskikh bolnykh. Radiologiya-praktika. 2004;(2):2630. [In Russian]. 